\title{
The pattern of mucocutaneous disorders in HIV infected children attending care and treatment in Tikur Anbesa specialized hospital, Addis Ababa, Ethiopia
}

\author{
Yichalal Endayehu ${ }^{1,3^{*}}$, Amha Mekasha ${ }^{1}$ and Firehiwot Daba ${ }^{2}$
}

\begin{abstract}
Background: Children with HIV infection may develop a wide variety of infectious and inflammatory diseases of the skin. These disorders are often more severe and more difficult to treat than in the immunocompetent child. In some cases, disorders of the skin or mucous membranes may provide an early clue to the presence of pediatric HIV infection.

Methods: It is a descriptive cross-sectional study which was conducted at the pediatric infectious disease unit, department of pediatrics and child health, Tikur Anbesa specialized Hospital. Clinical information was collected using a questionnaire. The data was analyzed using SSPS 16.0 version. Chi-squared was utilized where appropriate and a p-value of less than 0.05 was considered statistically significant.

Results: Two hundred seventy HIV infected children were recruited in this study. Out of these females were 51.5\% and males were 48.5\%. Most of the children 196/270 (72.6\%) were suffering from one or more mucocutanous disorders. The most prevalent mucocutanous disorders were infectious dermatosis. Overall, mucocutaneous disorders were more prevalent in advanced stages of HIV disease $P<0.001$. Two or more mucocutanous disorders were found in moderate and sever immunosuppression. Seventy three percent of the HIV-infected children with mucocutaneous disorders were already on HAART.
\end{abstract}

Conclusions: The prevalence of mucocutanous disorders is high in HIV infected children. Advanced immunosuppression is highly associated with a wide spectrum of mucocutanous disorders.

\section{Background}

Globally, there were a total of 33.2 million people living with HIV, in 2007, of which 2.5 million (7.5\%) were children under the age of 15 years [1]. Total number of deaths was 2.1 million, of which 330,000 were children. It is estimated that more than $90 \%$ of children living with human immunodeficiency virus (HIV) acquired the virus during pregnancy, birth, or breastfeeding, forms of HIV transmission that can be prevented [2].

In Ethiopia $44 \%$ of the population are children below 15 years. The adult prevalence of HIV is $7.7 \%$ in urban

\footnotetext{
*Correspondence: yiche2006@yahoo.com

'Department of Pediatrics and Child Health, College of Health Sciences, School of Medicine, Addis Ababa University, Addis Ababa, Ethiopia ${ }^{3} \mathrm{PO}$ Box 90074, Addis Ababa, Ethiopia

Full list of author information is available at the end of the article
}

and $0.9 \%$ in rural with average population prevalence 2.1\%. There are 134,586 children living with HIV/AIDS and out of whom more than 67,000 are estimated to be eligible for ART but only 4863 were taking HAART as of March 2008 [3].

Skin manifestations constitute one of the most common clinical features in such children and their clinical pattern and severity is more or less in accordance with their $\mathrm{CD}_{4}$ counts. Approximately $90 \%$ of patients will develop one or more skin diseases during the course of their illness and $37 \%$ of patients present with skin lesions as a marker of HIV infection [4]. Children with HIV infection are more prone to adverse cutaneous drug reactions, both to anti-retroviral therapy (ART) and to other drugs that are given concomitantly for co-morbid illnesses. Thus, an early recognition of such features is

\section{Ciomed Central}


important for an early diagnosis and also to assess the prognosis of HIV infection.

There are no data regarding prevalence and patterns of mucocutanous disorders among HIV infected children in Ethiopia. Some data from other nations are very limited and are mainly from adult cases. Extrapolating from adult cases is difficult because prevalence and pattern of mucocutanous lesions varies among children and adults. Thus, the objective of this study is to determine the prevalence and pattern of muocutanous manifestation of HIV/AIDS among children taking care and treatment in TikurAnbesa Specialized hospital (TASH).

\section{Methods}

\section{Source population}

All children who are followed up at the Pediatric Infectious Diseases Clinic, TikurAnbesa Specialized hospital during the study period.

\section{Study population}

All HIV infected children who are taking care and treatment at pediatric Infectious Clinic, Tikur Anbesa Specialized Hospital during the study time. The sample size is 196 calculated using the formula $z^{2} x p(1-p) / w^{2}$, estimated prevalence of $85 \%$ (taken from research done in Tanzania) with $95 \% \mathrm{CI}$, and $\mathrm{w}=0.05$.

All HIV infected children aged up to 14 years, who full filled the inclusion criteria (all children living with HIV/ AIDS and have been enrolled in care and treatment in Tikur anbesa hospital) and whose parents/guardians gave informed consent, were enrolled consecutively until the required sample size was obtained consecutively. HIV exposed infant where the infection was not confirmed, and children above 14 years of age who being managed on the adult clinic were excluded from the study.

\section{Study design}

This is a descriptive cross-sectional study which was conducted at the pediatric infectious disease unit, Department of pediatrics and child health, TikurAnbesa Specialized .Hospital. In the study, both new and repeat cases were evaluated thoroughly for occurrence of mucocutanous lesions by a senior pediatric (YE) resident in collaboration with dermatologist. Data was collected using standard pretested questionnaire.

Clinical staging was done according to the WHO pediatric staging of HIV/AIDS. While immunologic classification was done according to the CDC immunologic classification for HIV infected infants and children.

Dermatological examination was done in daylight. Diagnoses of most dermatoses were done clinically. Where necessary, appropriate laboratory tests like $\mathrm{KOH}$ from skin scraps and gram stain, culture and sensitivity from pus swabs were performed to confirm the diagnosis.

\section{Data collection}

All subjects had a complete history and physical examination and necessary diagnostic procedures from skin were done to confirm the diagnosis. Trained residents, nurses and data clerks working in PIDC were engaged for data collection and data entry.

\section{Data analysis}

Statistical analysis was done using the Statistical Package for Social Sciences (SPSS) program version 16.0. Chisquared test was used for categorical variables. A p-value of less than 0.05 was considered statistically significant.

Ethical clearance for this study was obtained from institutional research review board (IRB) of the college of health sciences. Anything that breaks the anonymity of the individual was avoided including name. Verbal assent from the child, and consent from the guardian or parent was obtained and confidentiality has been assured.

\section{Results}

A total of $270 \mathrm{HIV}$ infected children were recruited into the study. There were $48.5 \%(131 / 270)$ males and 51.5\% $(139 / 270)$ females. The age ranged from 2 months to 14 years (mean age 9.3 years with $3.5 \pm \mathrm{SD}$ ). All were from Addis Ababa.

Over all 72.6\% (196/270) had mucocutanous disorders. Almost males and females were equally infected with one or more mucocutanous lesions $(72.5 \%$ and $72.6 \%)$ respectively. The prevalence of mucocutanous disorders under 5 years age was $77.7 \%$, while for those greater than 5 years was $71.7 \%(\mathrm{p}$ value $=0.68)($ Table 1$)$.

There was a wide variety of mucocutanous disorder as shown in Table 2. Infectious dermatosis accounted for the majority of mucocutanous disorders $(82.6 \%)$ while noninfectious/inflammatory dermatosis accounted for $44.8 \%$ (Table 3). Many children had multiple skin conditions and were therefore counted more than once in certain situations.

Superficial fungal infections were the commonest conditions present in $51.8 \%$ followed by PPE in $44.2 \%$ of the

Table 1 Distribution of HIV infected children taking care and treatment by sex and age $(n=270)$

\begin{tabular}{lccc}
\hline Age groups & $\begin{array}{c}\text { Males } \\
\mathbf{n ~ ( \% )}\end{array}$ & $\begin{array}{c}\text { Females } \\
\mathbf{n ~ ( \% )}\end{array}$ & $\begin{array}{c}\text { Total } \\
\mathbf{n}(\%)\end{array}$ \\
\hline $0-5$ years & $20(15.3)$ & $16(11.5)$ & $36(13.3)$ \\
$5-10$ years & $45(34.3)$ & $56(40.2)$ & $101(37.4)$ \\
$10-14$ years & $66(50.3)$ & $67(48.2)$ & $133(49.2)$ \\
Total & $131(48.5)$ & $139(51.5)$ & $270(100)$ \\
\hline
\end{tabular}


Table 2 Mucocutanous disorders in HIV infected children attending PIDC, Tikur Anbesa Specialized Hospital $(\mathrm{n}=196)$

\begin{tabular}{lcc}
\hline Mucocutanous disorder & N & $\%$ \\
\hline Noninfectious inflammatory dermatosis & 88 & 44.8 \\
Papular pruritic rash (PPE) & 60 & 30.6 \\
Seborrhic dermatitis & 15 & 7.7 \\
Atopic dermatitis & 6 & 3 \\
Drug rash & 6 & 3 \\
Erythema nodosum & 1 & 0.5 \\
Infectious dermatitis & 162 & 82.6 \\
Superficial fungal infection & 102 & 51.8 \\
Tinea capitis & 55 & 28 \\
Tinea corporis & 34 & 17.3 \\
Tineaungum & 7 & 3.5 \\
Pityriasisversicolor & 2 & 1 \\
Oral thrush & 4 & 2 \\
Viral infections & 38 & 19.3 \\
Molluscum contagiosum & 27 & 13.8 \\
Herpes simplex & 2 & 2 \\
Herpes zoster & 4 & 1.5 \\
Chicken pox & 3 & 1,5 \\
Measles & 3 & 0.5 \\
Bacterial infections & 1 & 10.2 \\
Impetigo & 20 & 9.2 \\
Infestation (scabies) & 3 & 1 \\
\hline
\end{tabular}

children. The most frequent superficial fungal infection was tinea capitis, occurring in $28 \%$ while the least frequent was tinea (pityriasis) versicolor found in only two children (1\%). Viral and bacterial infection occurred in $19.3 \%$ and $10.2 \%$ of patients respectively. Among noninfectious dermatosis, PPE was the commonest (30.6\%) followed by seborrhic dermatitis (7.7\%) and the least frequent non infectious mucocutanous disorder was erythema nodosum. The commonest bacterial skin infection was impetigooccurring in $9.2 \%$.

Molluscum contagiosum found in $13.8 \%$, was the commonest viral infection, while measles present in only one child. Six children had drug rash induced by Nevirapine. There was no neoplasm encountered in this study.
The prevalence of mucocutaneous disorders was highest in the advanced paediatric WHO stages III (76.9\%) and IV (88.8\%) and relatively lower in stage II andI $61.2 \%$ and $55.5 \%$ respectively $(\mathrm{p}<0.001)$. Similarly children with severe immunosuppression by CDC criteria had the highest prevalence of mucocutaneous disorders (100\%), followed by those with moderate immunosuppression (70\%) while children with no evidence of immunosuppression had the lowest (48.3\%) prevalence $(\mathrm{p}<0.000)$. The mean CD4 count was low in children who have mucocutanous lesion $(456 \pm 285 \mathrm{sd})$ while those who has nomucocutanous disorder was $(646 \pm 270 \mathrm{sd})$ with $\mathrm{p}$ value $=0.026$ (Table 4).

Two and more mucocutanous lesions in one child were common with sever immunosuppression (34.8\%) followed by moderate immunosuppression (30\%) while children with no evidence of immunosuppression had lowest $(22 \%)$ with p value $=0.00$.

From 196 children who had mucocutanous disorders 141(72.6\%) were on HAART according to Ethiopian HIV/AIDS treatment guideline. Of these $32.6 \%$ had been on HAART for more than 12 months, while $20 \%$ and $19.4 \%$ were on HAART for less than 6 months and between 6 months and 12 months respectively.

\section{Discussion}

In this this study, $72.6 \%$ of HIV/AIDS pediatric patients attending care and treatment inTikurAnbesa Hospital had a wide range of mucocutaneous disorders. High prevalence of skin diseases among HIV infected children similar to this study has been reported in Tanzania (85\%) [5], Thailand (83\%) [6] and Cameroon (68.8\%) [7]. Other studies showed different results [8] the difference may be due to geographic variation and quality of care. A study by Luminus et al. showed that children less than five years of age are the least affected than the older ones, [9], but in our study there is no significant difference among younger and older children similar to that of Tanzanian study [5].

According to a study in Thailand the prevalence of mucocutanous disorder in sever, moderate and no evidence of immunosuppression was $62 \%, 43 \%$ and $20 \%$ respectively [10] and similar study in Tanzania showed $97 \%, 84.5 \%$ and $71 \%$ respectively. In this study, the prevalence of mucocutaneous disorders among children with severe, moderately severe and no evidence

Table 3 Distribution of mucocutanous disorder in HIV infected children by age

\begin{tabular}{|c|c|c|c|c|c|}
\hline \multirow[b]{3}{*}{ Mucocutanous disorder } & \multicolumn{5}{|c|}{ Age groups } \\
\hline & Less than 5 years & $5-10$ years & $10-14$ years & Total & $p$ value \\
\hline & $\mathrm{n}=28(\%)$ & $\mathrm{n}=71(\%)$ & $\mathrm{n}=97(\%)$ & $\mathrm{n}=196(\%)$ & \\
\hline Non infectious dermatosis & $10(35.7)$ & $33(46.4)$ & $45(46.4)$ & $88(44.8)$ & 0.62 \\
\hline Infectious dermatosis & 27 (96.4) & $56(78.8)$ & 79 (81.4) & $162(82.6)$ & 0.32 \\
\hline
\end{tabular}


Table 4 Prevalence of mucocutanous disorder among HIV infected children by WHO and CDC disease progression $(\mathbf{n}=\mathbf{2 7 0})$

\begin{tabular}{lccc}
\hline & $\begin{array}{c}\text { Mucocutanous disorder } \\
\text { Present } \mathbf{n = 1 9 6}\end{array}$ & $\begin{array}{c}\text { Mucocutanous disorder } \\
\text { Absent } \mathbf{n = 7 4}\end{array}$ & $\begin{array}{c}\text { Total } \\
\mathbf{n = 2 7 0}\end{array}$ \\
\hline WHO pediatric stage & $5(55.5)$ & & $\mathbf{p}$ value \\
I & $63(61.2)$ & $4(44.5)$ & $9(3.3)$ \\
II & $80(78)$ & $40(38.8)$ & $103(38.2)$ \\
III & $48(88.9)$ & $24(22)$ & $104(38.5)$ \\
IV & & $6(11.1)$ & $54(20)$ \\
Immunosuppression level by CDC & $44(48.3)$ & $47(51.7)$ & $91(33.7)$ \\
No evidence (category I) & $63(70)$ & $27(30)$ & $90(33.3)$ \\
Moderate (category II) & $89(100)$ & $0(0)$ & $89(33)$ \\
Sever (category III) & $456( \pm 285 \mathrm{sd})$ & $646( \pm 270)$ & 0.000 \\
Mean cd4 & & & 0.026 \\
\hline
\end{tabular}

of immunosuppression was $100 \%, 70 \%$ and $48.3 \%$ respectively and the differences were statistically significant $(\mathrm{p}<0.001)$. Most children with moderate and sever immunosuppression have two and more mucocutanous disorder [10]. Similarly our study showed two and more skin disorders were more common in advanced immunosuppression.

All of the above studies including ours indicate that the risk of acquiring mucocutaneous disorders for HIV infected children rises as the level of immunosuppression advance. In this study Infectious dermatosis are the most frequent cause of mucocutaneous disorders among HIV infected children like other studies [5]. In this study, the most common infectious dermatosis was superficial fungal infections and the most common non infectious dermatosis was prurritic popular eruption (PPE) similar to another study [5]. The increased incidence of skin infections is attributed to the depletion of the Langerhan's cells responsible for the mucocutaneous immunological system.non infectious dermatosis also become prevalent whenthere is immunosuppression [5,7].

Patients with HIV disease are particularly prone to hypersensitivity drug eruptions [11]. In our study 6 children (3\%) had moderate to severe drug rash secondary to nevirapine. kaposis sarcoma which is common cutaenous neoplasm in HIV infected adults is rare in children. In Tanzania study only one child was found to have kaposis sarcoma $[5,11]$. In this study there was no a case of kaposis sarcoma indicating cutanous neoplasms are rare in children.

Study done by Sibhatu B et al. on adherence to HAART in pediatric patients in Addis Ababa at different hospitals including Tikur Anbesa (Black Lion) Hospital was $86 \%$ which is low compared to other setups [12]. Some studies indicate that HAART decrease the prevalence of mucocutanous disorders especially viral infections in HIV infected individuals [13]. But in our study and Tanzanian study [5], there was no significant difference in the prevalence of mucocutanous disorder among children on HAART and pre-ART care. For ART to have a significant effect on mucocutaneous disorders, it needs to be administered for a longer period of time and patients should be adherent to treatment. In a study by Donic I. et al., it was found that the use of ART for about two years reduced significantly the presence of oral candidosis and seborrheic dermatitis [14].

This study is cross sectional which does not allow us to assess treatment response and course of mucocutanous disorder and to see effect of HAART.

\section{Conclusions}

From this study it can be concluded that there is a high prevalence of mucocutanous disorder in HIV infected children. Most of the mucocutanous disorders were secondary to infectious causes. Children with advanced immunosuppression are suffering from a wide spectrum of mucocutanous disorders. Thus it is recommended that mucocuatnous disorders being so common among HIV infected children thorough evaluation should be done in HIV care and treatment centers to address these problems.

\section{Competing interests}

The authors declare that they have no competing interests.

\section{Authors' contributions}

YTE conceived and involved in its design, data collection and write up. AWM advice, improve and supervise the study. FGD co-supervised the study and participated in the data collection. All authors read and approved the final manuscript.

\section{Acknowledgements}

We are very grateful to physicians, nurses and other staff working in PIDC involved for their full participation, data collection and support. Finally I would like to thank and appreciate parents, care takers and children for their willingness to participate in this study. 


\section{Author details}

'Department of Pediatrics and Child Health, College of Health Sciences, School of Medicine, Addis Ababa University, Addis Ababa, Ethiopia. ${ }^{2}$ Department of Dermatology and Venerology, College of Health Sciences, School of Medicine, Addis Ababa University, Addis Ababa, Ethiopia. ${ }^{3} \mathrm{PO}$ Box 90074, Addis Ababa, Ethiopia.

Received: 12 May 2013 Accepted: 22 October 2013

Published: 25 October 2013

\section{References}

1. UNAIDS/WHO: AIDS epidemic update: December 2007 UNAIDS/07.27E, JC1 322E. Geneva: UNAIDS; 2007.

2. UNAIDS: Report on the global AIDS epidemic August 2008. http://data.unaids. org/pub/globalreport/2008/20080715_fs_regions_en.pdf.

3. Guideline for the use of ART in children and adults update of 2006: http://AIDSinfo nih.gov.

4. Dlova N, Mosam A: Cutaneous manifestations of HIV/AIDS: part 1. South Afr J HIV Med 2004, 5:12-17.

5. Panya MF, Mgonda YM, Massawe AW: The pattern of mucocutaneous disorders in HIV-infected children attending care and treatment centres in Dar es Salaam, Tanzania. BMC Public Health 2009, 9:234-241.

6. Montri U, Tarunotai U: Cutaneous manifestations in children with HIV infection. A 5-year study in Vachira Hospital. Thai I Dermatol 2001, 17:167-174

7. Josephine M, Issac E, George A, Ngole M, Albert SE: Patterns of skin manifestations and their relationships with CD4 counts among HIV/AIDS patients in Cameroon. Int J Dermatol 2006, 45(3):280-284.

8. Seoane RE, Bellon JM, Gorbindo D, et al: Role of antiretroviral therapy in mucocutaneous manifestations in HIV infected children over a period of two decades. Br J Dermatol 2005, 153:382-389.

9. Luminus LM, Mardaresu M, Petrea S, et al: Cutaneous disorders in HIV infected children. Int Conf AIDS 1998, 12:574. Abstract No 32273[17].

10. Wananukul S, Deekajorndech T, Panchareon C, Thisyakorn U: Mucocutaneous findings in pediatric AIDS related to degree of immunosuppression. Pediatr Dermatol 2003, 20:289-294.

11. Mendiratta V, Mittal S, Jain A, Chander R: Mucocutaneous manifestations in children with human immunodeficiency virus infection. Indian $J$ Dermatol Venereol Leprol 2010, 76:458-466.

12. Biadgilign S, Deribew A, Amberbir A, Deribe K: Adherence to highly active antiretroviral therapy and its correlates among HIV infected pediatric patients in Ethiopia. BMC Pediatr 2008, 8(1):53.

13. Srikanth KP, Vijayakumar S, Aparna, Mallikarjun: A hospital based cross sectional study of mucocutaneous manifestations in the HIV infected. Int J Collab Res Internal Med Public Health 2010, 2(3):50-78.

14. Donic I, Vesic S, Jertoric DJ: Oral candidosis and seborrheic dermatitis in HIV infected patients on highly active antiretroviral therapy. HIV Med 2004, 5:50-54

doi:10.1186/1471-5945-13-12

Cite this article as: Endayehu et al:: The pattern of mucocutaneous disorders in HIV infected children attending care and treatment in Tikur Anbesa specialized hospital, Addis Ababa, Ethiopia. BMC Dermatology 2013 13:12

\section{Submit your next manuscript to BioMed Central and take full advantage of:}

- Convenient online submission

- Thorough peer review

- No space constraints or color figure charges

- Immediate publication on acceptance

- Inclusion in PubMed, CAS, Scopus and Google Scholar

- Research which is freely available for redistribution 